\title{
Evaluating the Effect of Slow-Stroke Back Massage on the Anxiety of Candidates for Cataract Surgery
}

Maryam Keramati, MD, ${ }^{1}$ Mohammad Sadegh Sargolzaei, $M s c,{ }^{2}$ Ali Moghadasi, ${ }^{3}$ Mohammad Hasan Basirinezhad, Msc, ${ }^{4}$ Reza Mohammadpourhodki*5

${ }^{1}$ School of Medicine, Mashhad University of Medical Sciences, Mashhad, ${ }^{2}$ Student Research Committee, School of Nursing and Midwifery, Iran University of Medical Sciences, Tehran, ${ }^{3}$ Petroleum Industrial Health Organization, Shiraz, ${ }^{4}$ Department of Epidemiology and Biostatistics, School of Public Health, Tehran University of Medical Sciences, Tehran,

${ }^{5}$ Department of Nursing, School of Nursing and Midwifery, Shahroud University of Medical Sciences, Shahroud, Iran

Background: The patients under cataract surgery often experience anxiety not only during the surgery, but also prior to the surgery.

Purpose: We sought to determine the effects of slow-stroke back massage on anxiety in patients undergoing cataract surgery.

Setting: The study was conducted in the Amiralmomenin Hospital of Zabol city, south-east of Iran.

Participants: A total of 60 candidates of cataract surgery participated in the study.

Research Design: The participants were randomly allocated to either control or intervention groups. The intervention group received slowstroke back massages, while patients in control group received routine interventions.

Intervention: The slow-stroke back massage was performed on the patients assigned to the intervention group. The intervention was performed in the morning of the surgery day at 30 minutes before the surgery. The researcher performed each massage session in a sitting position. The duration of each massage session was 15 minutes.

Main Outcome Measures: Anxiety was assessed in the both groups in the morning of the surgery, before and immediately after the intervention. Independent samples Student's $t$ test, paired samples Student's $t$ test, and chi-squared test were used to analyze the data.

Results: Anxiety was not significantly different between the two groups before and after the massage $(p=.816)$. On the other hand, paired samples Student's $t$ test showed a significant difference comparing the anxiety scores before $(49.7 \pm 5.43)$ and after (45.16 \pm 3.89$)$ the massage in the intervention group $(p<.001)$.

Conclusions: Based on our results, slow-stroke back massage, which is a low-cost and safe method, reduced anxiety in patients who were candidates for cataract surgery.

KEY WORDS: slow-stroke back massage; cataract; anxiety; surgery

\section{INTRODUCTION}

Among eye disorders, cataract is the most common cause of blindness worldwide. ${ }^{(1)}$ Cataract prevalence is $50 \%$ in the age group of $65-75$ years, reaching to $70 \%$ in those older than 75 years old. Currently, surgical intervention is the only treatment for cataract, with one million cataract surgeries annually performed in the United States. ${ }^{(2,3)}$

Patient's stress before surgery can lead to serious physiological and psychological reactions such as anxiety and fear, ${ }^{(4)}$ endangering the patient's life by promoting detrimental health effects such as hypertension and tachycardia. In fact, severe anxiety increases the risk of death by as much as three times. ${ }^{(5)}$ Various studies have shown that patients undergoing cataract surgery often experience fear and anxiety both prior and during the procedure. The pre-surgery anxiety negatively affects the patients' psychological and physiological performances. ${ }^{(6,7)}$ The findings of Vaughn et al. ${ }^{(8)}$ showed that despite the underscored strategies to reduce anxiety and its complications in patients undergoing cataract surgery, the patients are inadequately prepared from psychological perspectives by the nursing team. However, this may be due to the high number of patient admissions at the same day of the surgery. ${ }^{(9)}$

The current therapies for mitigating the physiological derangements triggered by anxiety are mainly based on pharmaceutical interventions, ${ }^{(10)}$ along with the administration of anti-anxiety drugs and tranquilizers prior to the surgery. Nevertheless, most drugs are associated with unwanted complications which are accentuated in elders who may simultaneously receive multiple drugs (i.e., polypharmacy). ${ }^{(11)}$ On the other hand, many of the currently used non-pharmacological practices pertain to the field of complementary medicine therapies. Research has shown that a variety of complementary medicine strategies can mitigate preoperative anxiety. ${ }^{(5)}$

Massage therapy is one of the most popular alternative and complementary therapies applied in clinical 
practice by nurses. This method is easy to implement, safe, non-invasive, and relatively cheap. ${ }^{(12)}$ The slowstroke back massage (SSBM) has been reported to be a simple, inexpensive, rapid, and non-invasive non-pharmaceutical technique that can be utilized as a nursing intervention, as well. ${ }^{(13)}$ SSBM is in fact a way of communication, recruiting sensory system (i.e., touching) instead of verbal method to interact with patients. ${ }^{(14)}$ In performing SSBM, the hands are gently moved on the skin without disturbing deep muscles. ${ }^{(15)}$ SSBM is applicable to the whole body, as well. SSBM usually starts slowly and in a rhythmic style from the posterior parts of the body and involves gentle movements of the hands on the patient's back at a speed of about 60 movements per minute, lasting about 3 to 10 minutes. The surface stroke movement used in this type of massage induces quite sensational effects and has very beneficial effects in patient relaxation. ${ }^{(16)}$ Massage is one of the most important complementary medicine therapies in nursing practice, and one of the indicators of comprehensive nursing care performed by skilled nurses. ${ }^{(17)}$ Massage therapy has been shown to be effective in managing anxiety in patients. ${ }^{(18,19)}$ A study conducted by Baron and Faubert ${ }^{(20)}$ showed that anxiety decreased after massage therapy. However, Albert et al. ${ }^{(21)}$ concluded that massage therapy was ineffective to significantly reduce anxiety.

Research has shown variable anxiety levels in patients undergoing cataract surgery. ${ }^{(22)}$ Anxiety greatly affects various patients' physiological and psychological functions. ${ }^{(7)}$ Nurses can particularly negate post-surgery complications, and the related financial expenses, by managing and reducing presurgery anxiety in patients. Many anxiety-reducing methods are available; however, the main point is to select the best and the safest method. Some protocols of complementary medicine can be effective in reducing anxiety. ${ }^{(19)}$ Massage is one of the most popular, easy to perform, safest, non-invasive, and affordable methods of complementary medicine to manage anxiety. ${ }^{(5)}$ Therefore, we here aimed to determine the effect of SSBM on the anxiety of patients undergoing cataract surgery.

\section{METHODS}

This was a randomized clinical trial study involving 60 candidates of cataract surgery referred to the Amiralmomenin Hospital of Zabol city in the southeast of Iran between August 2015 and March 2016. The patients were randomly allocated into either of the two groups: intervention ( 30 subjects) and control (30 subjects). After obtaining informed consent, the patients entered into the study. The inclusion criteria were diagnosis of cataract according to the medical records, being candidate for surgical intervention, being at least 40 years old, having no history of anxiety disorder and no consumption of relaxing and antianxiety medications on the night before the surgery, willingness to participate in the study, having full vigilance, acceptable listening and speaking abilities to answer questions, and having the severity of anxiety above 20 based on the Spielberger State-Trait Anxiety questionnaire. ${ }^{(23)}$ The exclusion criteria were either withdrawal or death of patient during the study. The sample size was determined by considering the mean difference between the intervention and control groups, as suggested by Jalalodini et al. ${ }^{(18)}$ The data were obtained using the Spielberger State-Trait Anxiety questionnaire. First, demographic information, including questions about the participants' age, sex, marital status, and educational level, was gathered by a brief checklist. Then, anxiety was determined by the Spielberger State-Trait Anxiety questionnaire which contained 20 questions with four possible answers organized in Likert scale (i.e., very low, low, high, and very high). ${ }^{(23)}$ The questionnaire was completed by interviewing the patients. The validity and reliability of the questionnaire have been universally verified, ${ }^{(24)}$ with the reported $\alpha$-Cronbach coefficients of 0.9452 and 0.9418 in normal and standard communities, respectively. ${ }^{(23)}$ The minimum and maximum scores were 20 and 80 , using this questionnaire. In this study, mild, moderate, and severe anxieties were assigned to the scores of 20-39, 40-59, and 60-80, respectively. ${ }^{(25)}$

The subjects were randomly allocated into either SSBM or control groups. The patients in both groups were interviewed for obtaining the demographic and anxiety information using the Spielberger State-Trait Anxiety questionnaire. The interviews were conducted in the morning of the surgery, before and immediately after the intervention. In the intervention group, after giving privacy to the patients, the stroke massage was conducted using warm and oily hands. The massager, in semi-sitting position, placed the palms and fingers of the both hands on the patient's occiput region, moving one hand parallel to the vertebral column toward lower body, executing low and superficial pressure until reaching the sacrum. Then, the second hand was moved the same way while returning the other hand to its start position. This protocol was followed throughout the massage. ${ }^{(26)}$ The researcher had massage therapy certification from an accredited agency. The researcher carried out the massages alone and in a quiet place. Each massage session lasted 15 minutes.

The members of control group received routine hospital-based educations, including a pamphlet providing information about cataract and the required cares before and after surgery. These patients received the required information from nurses verbally, as well. A full description of the study processes and importance was given to the patients, and informed consent was obtained from them. All the assessments were non-invasive. The study was approved by the Ethics Committee of Zabol University of Medical Sciences. 


\section{Statistical Analysis}

After completing the questionnaires, the items were coded and scored to be entered the statistical software. The data were analyzed in SPSS 22 software and reported using absolute and relative frequencies, as well as means and standard deviations. The chisquare, Fisher's exact test, as well as paired samples and independent samples Student's $t$ tests were used as statistical procedures. $P<.05$ was considered as the statistical significance threshold.

\section{RESULTS}

The randomization was performed at the study initiation. Our results indicated no significant differences in the patients' demographic features between intervention and control groups according to the chi-squared and Fisher's exact tests $(p>.05)$. Most of the subjects were males $(60 \%)$, married $(86.7 \%)$, self-employed $(73.3 \%)$, and lived in the city $(96.7 \%)$ (Table 1).

Independent samples Student's $t$ test showed no significant differences between the mean anxiety scores in the intervention and control groups before the intervention $(p=.0915$, Table 2$)$.

TABle 1. Demographic Profile of Patients in the Intervention and Control Groups

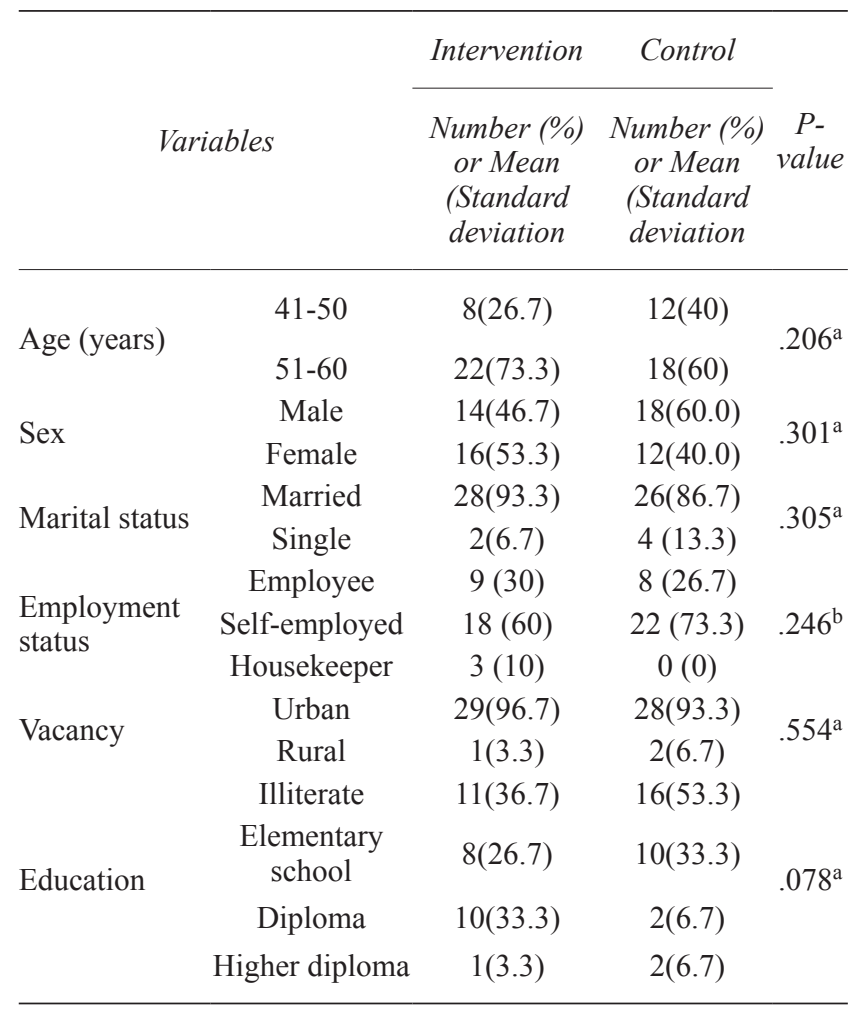

${ }^{a}$ Chi-squared test.

bFisher's exact test.
Paired samples Student's $t$ test was used to examine the patients' anxiety scores before and after the intervention in both groups. The results indicated that the anxiety score significantly decreased in the intervention group (SSBM) $(p<.001)$, but not in the control group $(p=.231$, Table 3$)$.

\section{DISCUSSION}

Our results revealed that the mean anxiety scores were not significantly different between the two groups before intervention. After SSBM, however, anxiety score decreased to the mild level in the intervention group, indicating a positive impact for this intervention in reducing the patients' anxiety. In line with this study, the results of Bauer et al., ${ }^{(26)}$ who examined the effects of massage therapy on the severity of pain and anxiety in patients undergoing cardiac surgery, showed that massage can reduce preoperative anxiety. In another study evaluating the effects of hand massage on preoperative anxiety in ambulatory surgery patients in the United states,

TABle 2. The Mean and Standard Deviation of Anxiety Score in Intervention and Control Groups Before and After Intervention

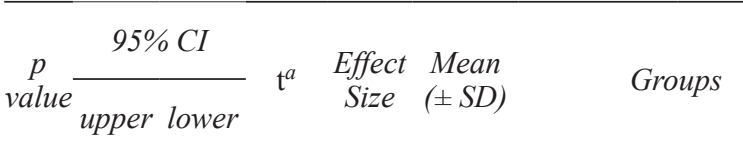

\begin{tabular}{|c|c|c|c|c|}
\hline \multirow{2}{*}{$\begin{array}{lll}0.095 & 5.44 & -0\end{array}$} & \multirow{2}{*}{2.54} & $\begin{array}{c}49.7 \\
( \pm 5.43)\end{array}$ & $\begin{array}{l}\text { Intervention } \\
\quad(\mathrm{n}=30)\end{array}$ & Pre- \\
\hline & & $\begin{array}{c}47.16 \\
( \pm 6.02)\end{array}$ & $\begin{array}{c}\text { Control } \\
(n=30)\end{array}$ & intervention \\
\hline \multirow{2}{*}{$0.8162 .003-2.543-0.23$} & \multirow{2}{*}{-0.27} & $\begin{array}{c}45.16 \\
( \pm 3.89)\end{array}$ & $\begin{array}{l}\text { Intervention } \\
\quad(\mathrm{n}=30)\end{array}$ & \multirow{2}{*}{$\begin{array}{l}\text { Post- } \\
\text { intervention }\end{array}$} \\
\hline & & $\begin{array}{c}45.43 \\
( \pm 5.02)\end{array}$ & $\begin{array}{c}\text { Control } \\
(\mathrm{n}=30)\end{array}$ & \\
\hline
\end{tabular}

andependent sample Student's $t$ test.

TABle 3. The Mean and Standard Deviation of Anxiety Score in Intervention and Control Groups Before and After Intervention

\begin{tabular}{|c|c|c|c|c|c|c|c|}
\hline $\begin{array}{c}p \\
\text { value }\end{array}$ & $95^{\circ}$ & $C I$ & $t^{a}$ & $\begin{array}{l}\text { Effect } \\
\text { Size }\end{array}$ & $\begin{array}{l}\text { Mean } \\
( \pm S D)\end{array}$ & \multicolumn{2}{|c|}{ Groups } \\
\hline \multirow{2}{*}{0.001} & 4.89 & 1.43 & 3.722 & 3.15 & $\begin{array}{c}49.7 \\
( \pm 5.43)\end{array}$ & $\begin{array}{c}\text { Pre- } \\
\text { intervention }\end{array}$ & \multirow{2}{*}{$\begin{array}{l}\text { Interventior } \\
(\mathrm{n}=30)\end{array}$} \\
\hline & 4.09 & 1.45 & 0.122 & 5.15 & $\begin{array}{c}45.16 \\
( \pm 3.89)\end{array}$ & $\begin{array}{c}\text { Post- } \\
\text { intervention }\end{array}$ & \\
\hline \multirow[b]{2}{*}{0.231} & \multirow[b]{2}{*}{4.19} & \multirow{2}{*}{-1.07} & & & $\begin{array}{c}47.16 \\
( \pm 6.02)\end{array}$ & $\begin{array}{c}\text { Pre- } \\
\text { intervention }\end{array}$ & \multirow{2}{*}{$\begin{array}{c}\text { Control } \\
(\mathrm{n}=30)\end{array}$} \\
\hline & & & 1.208 & 1.55 & $\begin{array}{c}45.43 \\
( \pm 5.02)\end{array}$ & $\begin{array}{c}\text { Post- } \\
\text { intervention }\end{array}$ & \\
\hline
\end{tabular}

aPaired sample Student's $t$ test. 


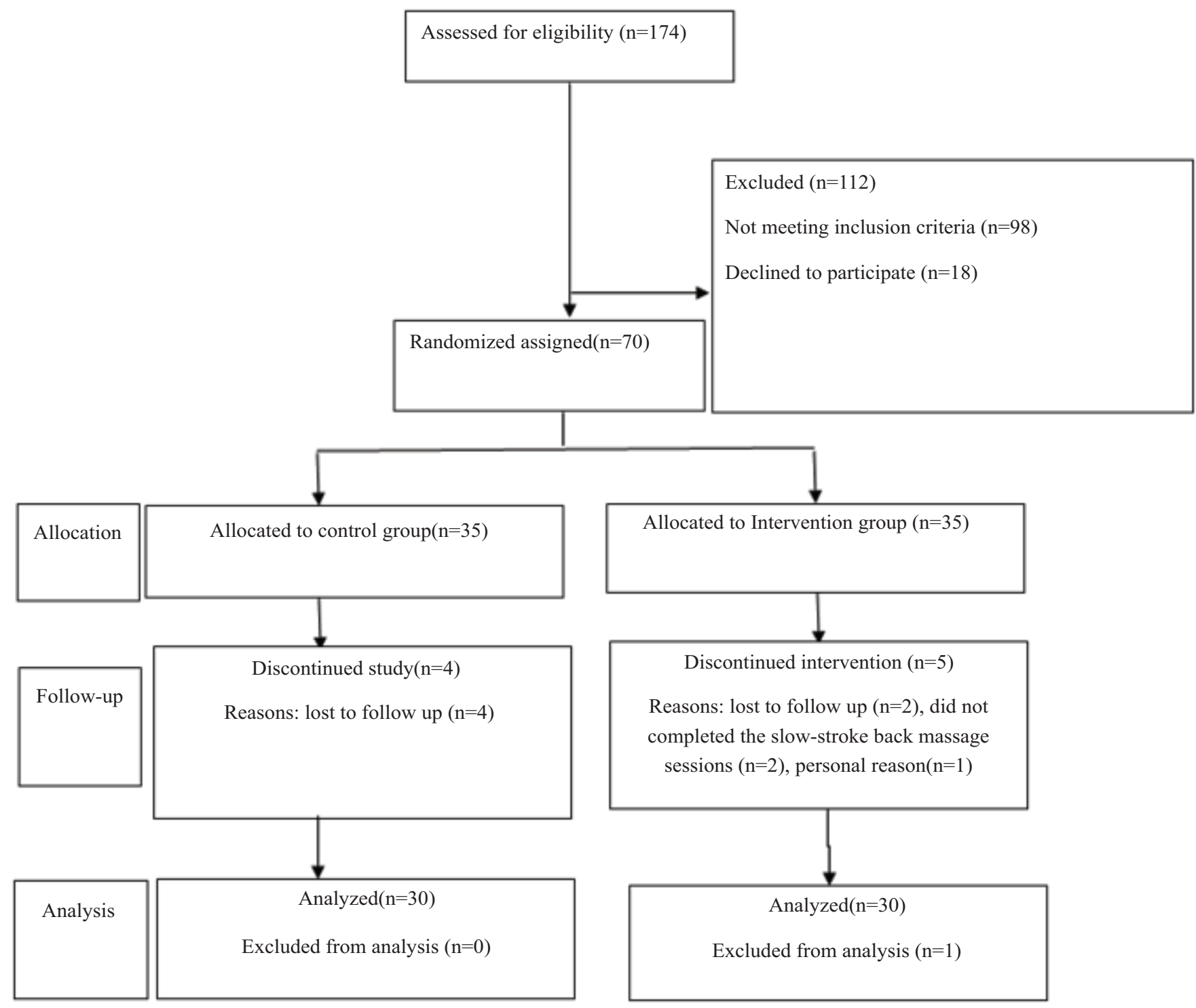

FIGURE 1. Study flow diagram.

the patients who received routine nursing care along with hand massage experienced lower anxiety. ${ }^{(27)}$ Gholami-Motlagh et al.(28) in their study compared the effects of two Swedish massage methods on vital signs and anxiety. Their findings indicated positive effects for the massages on both vital signs and anxiety. The results of the three above-mentioned studies are consistent with our findings. Razmjoo et al. ${ }^{(29)}$ examined the impact of foot massage on women's pain and anxiety after undergoing elective cesarean section. The results showed a significant difference in pain severity; however, anxiety was not affected by the massage therapy, unlike our findings. This may be due to different cultural aspects between the two studied populations and the nature of the surgeries. In another report by Ghezeljeh et al., ${ }^{(30)}$ massage intervention did not affect either anxiety or pain in patients with burns - which is also inconsistent with our findings. This discrepancy may also root in different study protocols and sample populations, as patients with burns experience higher levels of pain and anxiety. Nevertheless, Baron and Faubert ${ }^{(20)}$ showed that anxiety decreased following massage therapy. Furthermore, our results regarding the positive impacts of massage therapy on anxiety are consistent with the findings of Haun et al. ${ }^{(31)}$ and Dreyer et al. ${ }^{(32)}$

The limitation of this study included the inability to control potential intervening variables such as emotional, physical, cultural, and social factors which were beyond the researcher's control. In this study, we assessed the effects of SSBM as the massage therapy on anxiety level in our subjects. It is recommended to evaluate other variables, such as patients' satisfaction, to improve the assessment procedure. 


\section{CONCLUSION}

According to the results of the present research, massage is an effective non-pharmacological method to reduce anxiety in patients undergoing cataract surgery. Since nurses play an important role in treating and relieving anxiety in patients, it is advisable that they dedicate more time to patients undergoing cataract surgery and consider providing appropriate massage therapy settings for them. It is further recommended to investigate the effects of massage therapy in other groups of patients.

\section{ACKNOWLEDGMENTS}

Authors would like to thank Mostafa Dianatinasab, Epidemiologist at Shahroud University of Medical Sciences, for his invaluable contribution in the manuscript writing and for his careful reading and editing of the manuscript. The authors are thankful for the patients who participated in this study.

\section{CONFLICT OF INTEREST NOTIFICATION}

The authors declare there are no conflicts of interest.

\section{COPYRIGHT}

Published under the CreativeCommons AttributionNonCommercial-NoDerivs 3.0 License.

\section{REFERENCES}

1. Lam CK, Sundaraj K, Sulaiman MN. Virtual reality simulator for phacoemulsification cataract surgery education and training. Procedia Computer Sci. 2013;18:742-748.

2. Fazel F, Jelvani A, Farajzadegan Z. The trend of frequency of acquired cataract surgery among residents of Isfahan, Iran, admitted in Feiz Hospital. J Isfahan Med Sch. 2013;31(253).

3. Masoomi R. Epidemiologic study of patients receiving cataract surgeries in Alavi Hospital, Ardabil, 1999. J Ardabil Univ Med Sci. 2004;3(12):48-52.

4. Ghardashi F, Salehe Moghadam A, Hasanabadi H, Setayesh Y. Correlation between duration of waiting before surgery and anxiety of patients. Sci J Sabzevar Univ Med Sci. 2003;4:30.

5. FarmahiniFarahani M, Shamsikhani S, NorouziZamenjani M, Pourfarzad Z, Qolami M. The effect of hand massage on anxiety and physiological indicators before surgery. Complement Med J Faculty of Nurs Midwifery. 2017;7(1):1758-1766.

6. Bradt J, Dileo C, Shim M.. Music interventions for preoperative anxiety. Cochrane Database Syst Rev. 2013(6).

7. Marback R, Temporini E, Kara Júnior N. Emotional factors prior to cataract surgery. Clinics. 2007;62(4):433-438.

8. Vaughn F, Wichowski H, Bosworth G. Does preoperative anxiety level predict postoperative pain? AORNJ. 2007;85(3): 589-604.
9. Potter PA, Perry AG. Fundamentals of Nursing. Tehran, Iran: Jamenegar Publication; 2010.

10. Smeltzer SC, Bare B, Hinkle JL, Cheever KH. Brunner \& Suddarth's Textbook of Medical-Surgical Nursing, 12 ed. Tehran, Iran: Booshra Publication; 2009.

11. Valenzuela Milian J, Barren Serrano JR, Ornelas Aguirre JM. Anxiety in preoperative anesthetic procedures. Cirugia y Cirujanos. 2010;78(2):147-158.

12. Ahmadidarrehsima S, Mohammadpourhodki R, Ebrahimi $\mathrm{H}$, Keramati M, Dianatinasab M. Effect of foot reflexology and slow stroke back massage on the severity of fatigue in patients undergoing hemodialysis: a semi-experimental study. J Complement Integrat Med. 2018;15(4).

13. Holland B, Pokorny ME. Slow stroke back massage: its effect on patients in a rehabilitation setting. Rehabilitat Nurs. 2001;26(5):182-186.

14. Miladinia M, Baraz S, Shariati A, Malehi AS. Effects of slowstroke back massage on symptom cluster in adult patients with acute leukemia: supportive care in cancer nursing. Cancer Nurs. 2017;40(1):31-38.

15. Nahavandy Nejad S. Scientific Methods in Massage Therapy Education. Isfahan, Iran: Isfahan University of Medical Sciences Publications; 2007.

16. Shahdadi H, Hodki R, Abadi A, Sheikh A, Moghadasi A. The effect of slow stroke back massage on fatigue in patients undergoing hemodialysis: a randomized clinical trial. Int J Pharm Technol. 2016;8(3):16016-16023.

17. Taylor C, Lillis C, LeMone P, Lynn P. Fundmentals of Nursing: the Art \& Science of Nursing Care, $7^{\text {th }}$ ed. Philladelphia, PA: Lippincott Williams \& Wilkins; 2011.

18. Jalalodini A, Nourian M, Saatchi K, Kavousi A, Ghaljeh M. The effectiveness of slow-stroke back massage on hospitalization anxiety and physiological parameters in school-age children: a randomized clinical trial study. Iranian Red Crescent Med J. 2016;18(11).

19. Zadkhosh SM, Ariaee E, Atri A, Rashidlamir A, Saadatyar A. The effect of massage therapy on depression, anxiety and stress in adolescent wrestlers. Int J Sport Stud. 2015;5(3): 321-327.

20. Baron LJ, Faubert C. The role of Tai Chi Chuan in reducing state anxiety and enhancing mood of children with special needs. J Bodywk Movement Ther. 2005;9(2):120-133.

21. Albert NM, Gillinov AM, Lytle BW, Feng J, Cwynar R, Blackstone EH. A randomized trial of massage therapy after heart surgery. Heart \& Lung. 2009;38(6):480-490.

22. Saleh AR, Mohammadi SF, Vejdani M, Fallahi KM, Delbari A, Biglarian A. The impact of relaxation using guided imagery techniques on the physiological changes associated with anxiety in the elderly undergoing cataract surgery. J Sabzevar Univ Med Sci. 2018;24(6):29-35.

23. Mahram B. Standardization of Spielberger's State Anxiety Inventory in Mashhad, Iran [MA thesis]. Department of Phychology, AlameTabatabai University. Tehran, Iran: Tehran University of Medical Sciences; 1994.

24. Mohammadpourhodki R, Bagheri H, Basirinezhad MH, Ramzani H, Keramati M. Evaluating the effect of lifestyle education based on peer model on anxiety in patients with acute myocardial infarction. J Complement Integrative Med. 2019;Vol.16(1).Forthcoming 
25. Mohammadpoor HR, Rahnama M, Abdollahimohammad A, Shahraki VA, Shaamsizadeh, M. A comparison of the effect of training by peers and nurses on anxiety in patients with myocardial infarction: a randomized control trial. PCNM J. 2016;6(3):12-23.

26. Bauer BA, Cutshall SM, Wentworth LJ, Engen D, Messner PK, Wood CM, et al. Effect of massage therapy on pain, anxiety, and tension after cardiac surgery: a randomized study. Complement Ther Clin Pract. 2010;16(2):70-75.

27. Brand LR, Munroe DJ, Gavin J. The effect of hand massage on preoperative anxiety in ambulatory surgery patients. AORN J. 2013;97(6):708-717.

28. Gholami-Motlagh F, Jouzi M, Soleymani B. Comparing the effects of two Swedish massage techniques on the vital signs and anxiety of healthy women. Iranian J Nurs Midwifery Res. 2016;21(4):402.

29. Razmjoo N, Hafizi LL, Yousefi F. Effect of foot reflexology on pain and anxiety in women following elective cesarean section. The Iranian J Obstetr Gynecol Infertility. 2012;1:9-17.
30. Ghezeljeh TN, Ardebili FM, Rafii F, Manafi F. The effect of massage on anticipatory anxiety and procedural pain in patients with burn injury. World J Plastic Surg. 2017;6(1):40.

31. Haun JN, Graham-Pole J, Shortley B. Children with cancer and blood diseases experience positive physical and psychological effects from massage therapy. Int $J$ Therapeut Massage \& Bodywk. 2009;2(2):7.

32. Dreyer NE, Cutshall SM, Huebner M, Foss DM, Lovely JK, Bauer BA, et al. Effect of massage therapy on pain, anxiety, relaxation, and tension after colorectal surgery: A randomized study. Complement Therap Clin Pract. 2015;21(3):154-159.

Corresponding author: Reza Mohammadpourhodki, Department of Nursing, School of Nursing and Midwifery, Shahroud University of Medical Sciences, Shahroud, Iran

E-mail: rezamdpour@shmu.ac.ir 